\title{
Response surface optimisation for the extraction of phenolics and flavonoids from a pink guava puree industrial by-product.
}

\begin{abstract}
Pink guava puree industry produces huge amount of by-products that have potential as sources for polyphenols. Response surface methodology was implemented to optimise the extraction conditions for phenolics (Y1) and flavonoids (Y2) from a by-product of the guava industry. A three-factor inscribed central composite design was employed to determine the effects of three independent variables, namely $\mathrm{pH}(\mathrm{X} 1: 2-6)$, temperature $\left(\mathrm{X} 2: 40-60{ }^{\circ} \mathrm{C}\right)$ and time $(\mathrm{X} 3: 1-5 \mathrm{~h})$, on the response variables. The corresponding predicted values for phenolics and flavonoids were 336.30 and $427.35 \mathrm{mg} 100 \mathrm{~g}-1$, respectively. Predicted values for extraction rates of phenolics agreed well with experiment values; R2 of 0.902 . However, the model derived for flavonoids extraction was less reliable; R2 of 0.983 . Increase in time and temperature was found significant in increasing the extraction rate. The optimum conditions for extracting phenolics by ethanolic solvent occurred at a $\mathrm{pH}$ of 2 and $60{ }^{\circ} \mathrm{C}$ for a $5-\mathrm{h}$ extraction.
\end{abstract}

Keyword: Extraction; Flavonoids; Phenolics; Psidium guajava by-products; Response surface methodology. 